\title{
Increasing engagement and participation in a large, third-level class setting using co-teaching
}

\author{
Farrell, Ann Marie ${ }^{a}$ and Logan, Anna ${ }^{a}$
}

${ }^{a}$ School of Inclusive and Special Education, Institute of Education, Dublin City University

\begin{abstract}
This study focused on the collaborative practice of two teacher educators who implemented a co-teaching intervention with a large class of first-year student teachers. The research arose from the teacher educators' wish to increase the range and nature of participation of students in the large class setting and to model co-teaching for the students who would be expected to engage in such practice themselves in primary schools. The aims of the study were to explore the use of co-teaching in the large class context as a support for student participation and students' meta-learning about co-teaching. In three separate 50-minute workshops, students were provided with samples of a child's work and were required to work in pairs or groups of three in order to come to conclusions about his current level of performance and to develop possible learning targets arising. Data were collected using a short, online survey.
\end{abstract}

The student cohort was very positive in terms of the effectiveness of the coteaching approach in helping them to understand the concepts and allowing more active engagement. Further, students were able to articulate their learning with regard to using the co-teaching approach. From the researchers' perspectives co-teaching was very useful in terms of increasing student participation and replicating a learning context that might be more usual with much smaller groups. Further, it allowed for provision of formative feedback both during and following the co-taught sessions that would not otherwise have been feasible. Finally, it allowed the student voice to be heard within the large class context.

Keywords: Co-teaching; collaborative practice; initial teacher education; student engagement; large class. 


\section{Introduction}

Internationally, there appears to be evidence that class size is increasing in universities (Kerr, 2011; Prosser \& Trigwell, 2014), giving rise to concerns about levels of student participation and engagement and, therefore the quality of teaching and learning (Cuseo, 2007; Fenollar, Roman \& Cuestas, 2007). Often, it is assumed that the there is only one teaching approach to be used in such a setting i.e. the traditional lecture whereby the teacher talks for the duration and the students listen. However, that assumption is under scrutiny (Prosser \& Trigwell, 2014; Teaching and Educational Development Institute, 2003) with examination of a wider range of teaching approaches which could be employed. The focus of this co-teaching intervention was a class of 400 first-year student teachers who were engaged in a module focusing on inclusion of pupils with special educational needs (SEN) in a primary, initial teacher education (ITE) programme.

\section{Theoretical Framework for Co-Teaching Large Classes}

Reconceptualising ITE involves, amongst other things, consideration of how student teachers learn and therefore how teacher educators teach. The absence of specific education or training for teacher educators mirrors that of third level educators in other fields. "The idea seems to be that one learns the profession through trial and error...this is highly remarkable in an area where professional development is the operative word" (Koster \& Korthagen, 2001, p. 240). Therefore, it is hardly surprising that, traditionally, the focus of teacher educators has been on themselves and their own needs rather than the needs of their students. Moreover, teacher educators are in the unique position in that they model the very practice they are trying to nurture in everything they do as well as everything they say (Hallett, 2010). This is opportunity that may not be exploited due to lack of awareness, focus on knowledge expertise and the actual structures of the teaching day in the university context.

Co-teaching is an accepted approach to effective teaching and learning in primary and postprimary settings, particularly in relation to addressing diversity of need and therefore increasing inclusion of all students (Gately \& Gately, 2001). There are six accepted models (Dieker, Finnegan, Grillo \& Garland, 2013) namely station teaching, parallel teaching, alternative teaching, one teach - one observe, one teach - one assist and teaming (Friend, 2016). In station teaching students rotate in three or more groups between teachers, each of whom is responsible for teaching part of the content in a given lesson at a station. In parallel teaching, the class is divided into two groups with each teacher working with one group only, while in alternative teaching one teacher teaches most of the class while a second teacher works with a small group providing additional support to some. In both the one teach - one assist and one teach - one observe models the class remains in one group 
with one teacher in a lead role while the second teacher respectively observes or provides brief individual assistance to students as required. Finally, teaming is characterized by both teachers jointly working with the group integrating their input and co-constructing teaching. The application of these models may depend on several factors including the nature of content being taught and learned, the educational setting in which the learning is taking place and/or the number, type and experience of the teachers implementing the strategy. However, co-teaching in the university context is a little explored activity and it remains unclear how this typology of co-teaching might apply in higher-education (Nevin, Thousand \& Villa, 2009). Furthermore, how teaching staff interact with each other in the university is poorly understood and there are "no models for research that assess the impact on student achievement when professors co-teach" (Nevin et al. 2009, p. 573). In the context of a teacher education programme, it is important that this deficit is addressed so that student teachers can see co-teaching being used before embarking on a career in which this is expected of them.

\section{Methodology}

The initial impetus for this study was the extension of the BEd from a three-year to a fouryear programme, resulting in the reconceptualising and reorganisation of the input on special and inclusive education (SIE). Arising from this, SIE is addressed using explicit, permeated and specialist models. The focus of this study is on a module wherein SIE is explicitly addressed in the first year of the programme. The authors designed a co-teaching intervention with a first year Bachelor of Education (BEd): Primary Teaching cohort of students with the intention of increasing participation in a workshop-based context. We hoped this would allow students to work on some quite complex skills and concepts in relation to diagnostic assessment of an individual child's work and writing learning targets arising from this. (See Table 1 for details).

We wished to provide hands-on experience of this type of assessment and planning at the outset of the programme so that student teachers would carry an understanding of the importance of focusing on the individual as well as the group/class from the beginning of their ITE journey. Further, we hoped that the workshop style format would provide an opportunity to use assessment for learning ( $A f L$ ) techniques so that (a) formative feedback could be provided to students and (b) to inform our own teaching in terms of focus of content and teaching approaches. While the initial impetus arose from the programmatic changes, the specific aims of the study were to explore the use of co-teaching as a strategy to increase student participation in the workshops and to model co-teaching for the students who would be expected to engage in such practice themselves in primary schools. Table 1 outlines the detail of the three workshops. 
Table 1: Details of Workshops, Assessment Approaches and Data Collection

\begin{tabular}{|c|c|c|c|}
\hline $\begin{array}{c}\text { Workshop } \\
\text { Number }\end{array}$ & Workshop Focus & $\begin{array}{l}\text { Assessment } \\
\text { Approaches }\end{array}$ & Data Collection \\
\hline 1 & $\begin{array}{l}\text { Analysed a pupil profile } \\
\text { Analysed a child's work (diagnostic } \\
\text { assessment) to identify patterns of } \\
\text { accuracy and error leading to } \\
\text { identification of strengths and } \\
\text { needs. Four samples of work were } \\
\text { used in-class with students working } \\
\text { in pairs or } 3 \text { s on one of four } \\
\text { samples. All samples available on } \\
\text { Moodle. }\end{array}$ & $\begin{array}{l}\text { In all three } \\
\text { workshops: } \\
\text { Students' work was } \\
\text { collected and was } \\
\text { feedback provided } \\
\text { in class and } \\
\text { afterwards on } \\
\text { Moodle using a } \\
\text { sample of responses. }\end{array}$ & $\begin{array}{l}\text { Students surveyed } \\
\text { at the end of the } \\
\text { module. }\end{array}$ \\
\hline
\end{tabular}

Each workshop comprised three stages. First, we provided a short introduction to the topic and explained the workshop task. Then students completed the tasks in pairs and threes and finally we took feedback from students. In the absence of research relating to the implementation of the six models of co-teaching in higher education and in the spirit of an exploratory study we adopted a flexible and pragmatic approach to designing our approach. The large lecture theatre context precluded the option of dividing the class into separate groups and consequently we relied mainly on those models that involved us working together with the entire group. As such we used the one teach - one assist, one teach - one observe and teaming models. In the first stage of each workshop we alternated the role of lead teacher and assistant/ observer while introducing the content and explaining the task. In the second stage, while the students worked on the tasks, we each circulated observing student participation and offering assistance as required. In the final stage we used teaming extensively, eliciting and recording student feedback for display and providing alternative analyses and commentary on student work.

Students were invited to evaluate the intervention to determine if they believed the strategy helped them to effectively access and learn the concepts being targeted in the workshops and to ascertain what they learned about co-teaching as a strategy in itself. A short, online, questionnaire survey consisting of two likert questions and four open ended questions was used. The total number of respondents was 156, giving a response rate of 39\%. Qualitative data were analyzed using a grounded theory approach (Glaser \& Strauss, 1999). In total 
337 responses to the questions What did you learn about co-teaching as a strategy? $(n=191)$ and How effective was co teaching in helping you to learn the concepts targeted? $(\mathrm{n}=146)$ were analyzed and coded by hand to identify emerging categories. Some respondents made more than one comment in response to either or both question and therefore, their comments may have been attributed to more than one code during analysis. The key themes emerging related to the co-teacher role and relationship and student perceptions of the impact on their learning.

\section{Findings}

The findings are presented below under the two key themes, with data from likert questions interwoven with the qualitative data from the open questions.

\subsection{Role and relationship of co-teachers}

Students were asked to rate their perceptions of the familiarity of the two lecturers with the learning content and processes.

Table 2. Responses to the question 'To what extent did you feel the two lecturers were familiar with the learning content and learning processes?'

\begin{tabular}{ccccc}
\hline $\begin{array}{c}\text { Very } \\
\text { familiar }\end{array}$ & Familiar & Not sure & $\begin{array}{c}\text { Not very } \\
\text { familiar }\end{array}$ & $\begin{array}{c}\text { Not at all } \\
\text { familiar }\end{array}$ \\
\hline $36 \%$ & $52 \%$ & $10 \%$ & $1 \%$ & $0 \%$ \\
\hline
\end{tabular}

Most students (88\%) felt that the lecturers were 'very familiar' or 'familiar' with the content (Table 2). Responses to the question 'What did you learn about co-teaching as a strategy? ' went some way to contextualising the qualitative findings in Table 2, particularly because of students' insights into the relationship between the two teachers.

Fifteen per cent of students perceived that teachers needed to be very organised, have planned well and have good communication skills to be effective in the co-teaching context: "both teachers were so prepared and organised in delivering the task" (Respondent \# 69)"; "A lot of cooperation is needed. The two teachers must have a good relationship" (Respondent \#90). It needs to be organised between people co-teaching. Both need to know their role during it in order for the strategy to be carried out effectively" (Respondent \#102). . Some students (11.5\%) identified the usefulness of co-teaching in enabling the teachers to provide support and help for the students during the class. "It 
allows the teacher to get to know pupil's abilities, as in such a big group as this module, it was easier to ask questions and get feedback." (Respondent \#140) A small number of students $(3.8 \%)$ referred to the equality of roles, with some commenting on the lack of equality while others perceived a good balance of interaction between the two teachers.

In the main, the range of views offered both mirrored and informed the perceptions of the two co-teachers themselves. While we understood the benefits of co-teaching and had used it to good effect before, it was always in the context of much smaller groups of up to about fifty students. We were apprehensive in terms of entering into this intervention because of the large class size and the fear that what worked with smaller groups could not be scaled up easily and might actually be very ineffective. However, as we moved through the three sessions, our confidence increased because of the high quality of work we were gathering from the students. We used AfL to inform our own teaching and could see the progress our students were making. As the students noted, we were able to provide much more focused and detailed support and feedback, both in-class and online afterwards on Moodle. In addition, we thoroughly enjoyed the experience of working with each other precisely because of the sense of support and also, because it enabled each of us to bounce ideas off each other, thereby learning from each other and enhancing our teaching skills and knowledge base.

\subsection{Impact on Student Learning}

Table 3 illustrates responses to the question 'How useful were the co-taught sessions to you as a learner?' Overall, 76\% of students indicated that they found the co-taught sessions useful or very useful. Again, these statistics were contextualised by the qualitative data arising from the open questions on the survey.

Table 3: Responses to the question ' How useful were the co-taught sessions to you as a learner?

\begin{tabular}{ccccc}
\hline Very useful & Useful & Not Sure & $\begin{array}{c}\text { Not very } \\
\text { useful }\end{array}$ & $\begin{array}{c}\text { Not at all } \\
\text { useful }\end{array}$ \\
\hline $33 \%$ & $53 \%$ & $14 \%$ & $7 \%$ & $0 \%$ \\
\hline
\end{tabular}

Some of the data arising from the question 'What did you learn about co-teaching as a strategy?' related specifically to student learning as well as the role of the two teachers as outlined above. Seventeen percent of students responding to this question identified the experience of gaining the insights and opinions of two people as being an important 
characteristic of co-teaching. Fourteen percent identified the increased participation of students in the large class setting as important with a further $2.5 \%$ highlighting its usefulness for enabling a workshop format in the large class "Enables a more interactive session between teacher and students. More interaction amongst peers with the topic rather than consuming information all at once." (Respondent \#156) "It's an effective methodology for teachers as it encourages interaction and keeps students actively engaged." (Respondent \#70). Some students (11.5\%) perceived the model as useful to allow the teachers the opportunity to engage with and support students during the class and $2.5 \%$ cited the provision of opportunity for modelling the strategy as useful.

When specifically asked 'How effective was the strategy in helping you to learn the concepts targeted?' the nature of the impact on student learning from their perspective became clearer. Firstly, most of the comments (76\%) could be attributed to the perception that the use of co-teaching had enhanced the learning experience. "Very effective as the two lecturers were very knowledgeable on the topics so they were able to answer all questions. The two lecturers were on either side of the room so they could give feedback on answers." (Respondent \#141) "I found the co-teaching workshops very helpful. It allowed more time to discuss our feedback and share ideas, which I found particularly helpful." (Respondent \#147). Students $(22.5 \%)$ indicated that the model increased their participation and attention in the large class setting "I found it very effective because I liked how by changing teachers I found it easier to keep my concentration.” (Respondent \#59). Ten percent of students indicated that the co-taught approach had a direct impact on what they were doing during the session. "It was great. Because it was easier to ask questions, because there wasn't just one teacher." (Respondent \#128)

Fourteen percent of respondents indicated that what the teachers were actually doing during the workshops enhanced their learning. Examples of such actions were filling in gaps in each other's commentary; management of feedback during the class; organisation of the content and materials in such a way that the student could concentrate on their learning rather than managing the materials themselves. "Very effective. I liked when one went around getting feedback and the other person typed. If one person didn't mention something or forgot something the other person was there to say it." (Respondent \#148)

\section{Conclusions}

Overall, the perceptions of the students regarding the co-taught workshop intervention was very positive. Students noted the impact on their learning reflecting the findings of the positive impact of co-teaching on learning in post primary and primary schools (Dieker at al., 2013; Friend, 2016). Further, seeing co-teaching modelled by the two teaching staff (Hallett, 2010) allowed students to extrapolate for themselves some characteristics of the 
practice. Students identified the extra support and feedback provided within and after the workshops as important to the development of their understanding of the threshold concepts of diagnostic assessment and writing learning targets. From the perspective of the coteachers, the approach was also effective and rewarding (Nevin et al., 2009). We could provide formative feedback in a detailed and meaningful manner scaffolding student learning and aligning learning outcomes, teaching strategies and assessment within the module itself. Engagement in co-teaching certainly led to "increased feelings of worth, renewal, partnership and creativity" (Gately \& Gately, 2001, p.40), directly impacting on our practice going forward.

While this was a small-scale study which is limited in that it relied primarily on self reporting by students we contend that it provides some insight into student perceptions of co-teaching. Furthermore, it led to a reorganisation of the approach the following year with a new cohort of students. This phase was also evaluated from the perspective of the student cohort but the findings arising were complemented by peer-observation and analysis of video recordings of the taught sessions . Nevertheless, further studies are needed to close the recognized gap in knowledge of co-teaching in higher education and in particular the impact on student achievement when faculty co-teach (Nevin et al., 2009).

\section{References}

Cuseo,J. (2007). The empirical case against large class size: Adverse effects on the teaching, learning and retention of first-year students, Journal of Faculty Development, 21(1), 5-21.

Dieker, L., Finnegan, L., Grillo, K., \& Garland, D. (2013) Special education in the science classroom. Science Scope, 37, 4, 18-22.

Fenollar, P., Roman, S., \& Cuestas,P. (2007). University students' academic performance: An integrative conceptual framework and empirical analysis. British Journal of Educational Psychology, 77 (4), 873-891.

Friend, , M. (2016) Welcome to co-teaching 2.0. Educational Leadership, 73, 4, 16-22.

Gately, S., \& Gately, F. (2001). Understanding co-teaching components. TeachingExceptional Children, 33, 4, 40-48.

Glaser, B. , \& Strauss, A. (1999). Discovery of Grounded Theory: Strategies for Qualitative Research. Chicago: Aldine.

Hallett, F. (2010). Do we practice what we preach? An examination of the pedagogical beliefs of teacher educators. Teaching in Higher Education, 15(4). 435448.

Kerr, A. (2011). Teaching and Learning in Large Classes at Ontario Universities: An Exploratory Study. Toronto: Higher Education Quality Council of Ontario. 
Koster, B., \& Korthangen, F. (2001). Training teacher educators for the realistic approach. In F.A.J. Korthagen (Ed.). Linking practice and theory: The pedagogy of realistic teacher education. (pp. 239-253). New Jersey: Lawrence Erlbaum Associates.

Nevin, A.I., Thousand, J.S., and Villa, R.A. (2009). Collaborative teaching for teaching educators what does the research say? Teaching and Teacher Education, 25(4), pp. 569574.

Prosser, M., \& Trigwell, K. (2014). Qualitative variation in approaches to university teaching and learning in large first-year classes, Higher Education, 67, 783-798.

Teaching and Educational Development Institute (2003). Teaching Large Classes Project 2001: Final Report. University of Queensland: Australia. 